\title{
ChemComm
}

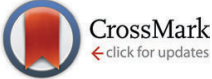

Cite this: Chem. Commun., 2016, 52,5565

Received 3rd February 2016 Accepted 16th March 2016

DOI: $10.1039 / c 6 c c 01107 a$

www.rsc.org/chemcomm

\section{Halogen bonding between metal centers and halocarbons $\dagger$}

\author{
Daniil M. Ivanov, ${ }^{a}$ Alexander S. Novikov, ${ }^{a}$ Ivan V. Ananyev, ${ }^{b}$ Yulia V. Kirina ${ }^{a}$ and \\ Vadim Yu. Kukushkin*a
}

\begin{abstract}
Metal-involving halogen bonding was detected in a series of associates of $\mathrm{CHI}_{3}$ with trans-[PtX $\left.\left(\mathrm{NCNAlk}_{2}\right)_{2}\right](\mathrm{X}=\mathrm{Cl}, \mathrm{Br})$. The $\mathrm{HI}_{2} \mathrm{C}-\mathrm{I} \cdots \eta^{1}{ }_{(\mathrm{Pt})}$ halogen bonding and the bifurcated $\mathrm{HI}_{2} \mathrm{C}-\mathrm{I} \cdots \eta^{2}{ }_{(\mathrm{Pt}-\mathrm{Cl})}$ halogen bonding - the latter undergoes the thermally induced reversible $\mathrm{HI}_{2} \mathrm{C}-\mathrm{I} \cdots \eta^{2}{ }_{(\mathrm{Pt}-\mathrm{Cl})} \rightleftarrows \mathrm{HI}_{2} \mathrm{C}-\mathrm{I} \cdots \eta^{1}{ }_{(\mathrm{Pt})}$ transformation - were observed and confirmed theoretically.
\end{abstract}

Halogen bonding (XB), among various non-covalent weak interactions, is one of the most intensively studied systems in modern science. Together with hydrogen bonding, $\pi-\pi-$, and metallophilic interactions, it is successfully applied in crystal engineering $^{1,2}$ and design of compounds exhibiting pharmacological significance. ${ }^{3-5}$ Recent applications of XB include stabilization of explosives ${ }^{6}$ and molecular design of materials with tunable photophysical properties. ${ }^{7,8}$

In accord with the IUPAC definition, $\mathrm{XB}^{9}$ is the real $\mathrm{R}-\mathrm{X} \cdots \mathrm{Y}$ $(\mathrm{X}=$ halogen $)$ contact, when, firstly, the interatomic distance between $\mathrm{X}$ and an appropriate nucleophilic atom of $\mathrm{Y}(\mathrm{Y}=\mathrm{F}, \mathrm{O}$, $\mathrm{N}, \mathrm{Cl}$, etc.) is less than the sum of their van der Waals radii and, secondly, the $\angle(\mathrm{R}-\mathrm{X} \cdots \mathrm{Y})$ angle is close to $180^{\circ}$ (exceptions from the linearity have been reviewed ${ }^{10}$ ). These geometrical parameters are usually easily obtained using single-crystal X-ray diffraction (XRD), which is the most common method for the detection of $\mathrm{XB}$. When application of the two criteria in XRD data fails, some other criteria (lengthening of $\mathrm{R}-\mathrm{X}$ covalent bonds due to $\mathrm{XB}$ and also changes in the appropriate spectroscopic parameters $\left.{ }^{9}\right)$, or

\footnotetext{
${ }^{a}$ Institute of Chemistry, Saint Petersburg State University, Universitetskaya Nab., 7/9, 199034, Saint Petersburg, Russian Federation. E-mail: v.kukushkin@spbu.ru

${ }^{b}$ A. N. Nesmeyanov Institute of Organoelement Compounds, Russian Academy of Sciences, Vavilova St., 28, 119991, Moscow, Russian Federation

$\dagger$ Electronic supplementary information (ESI) available: Synthesis of complexes (Section EX1), their co-crystallization with iodoform, full description of XRD experiments, crystallographic data and refinement parameters (Section EX2), full description of the geometrical parameters of covalent bonds and non-covalent interactions (Sections XR1-XR3), and full description of the results of theoretical calculations and computational details (Sections TH1-TH3). CCDC 14466561446670. For ESI and crystallographic data in CIF or other electronic format see DOI: $10.1039 / \mathrm{c} 6 \mathrm{cc} 01107 \mathrm{a}$
}

application of some other indirect methods, e.g. UV-vis, IR and Raman spectroscopy, ${ }^{11,12}$ differential anomalous X-ray scattering studies ${ }^{13} \mathrm{NMR}^{14,15}$ and phosphorescence ${ }^{7}$ spectroscopy, were also applied for XB recognition.

In the majority of the reported cases when $\mathrm{XB}$ was reliably identified, only typical Lewis basic non-metal atoms bearing lone pairs (viz. O, N, S, halogens etc.) behave as XB acceptors, whereas possible XBs with metal centers was found only for $\mathrm{I}_{2} \cdot{ }^{16-19}$ Our inspection of the relevant literature indicates few experimental studies describing $\mathrm{X} \cdots \mathrm{M}$ short contacts, which were either not considered as halogen bonds, or their geometrical parameters fulfill only one of the two aforementioned structural IUPAC criteria. Therefore definitive attribution of these weak interactions to XB was not provided and the other IUPAC criteria should be applied for their identification. Indeed, Chen et al. ${ }^{20}$ Wölper et al. ${ }^{21}$ and Laguna et al. ${ }^{22}$ observed $\mathrm{X} \cdots \mathrm{Au}^{\mathrm{I}}$ and $\mathrm{X} \cdots \mathrm{Ag}^{\mathrm{I}}$ contacts, which fulfilled only the "van der Waals criterion", but in all the three cases the corresponding $\mathrm{R}-\mathrm{X} \cdots \mathrm{M}$ angles strongly deviate from $180^{\circ}$ (by $30-90^{\circ},{ }^{20} 60-70^{\circ},{ }^{21}$ and $85^{\circ 22}$ ) thus contrasting with the second structural IUPAC criterion. Yamamoto et al. ${ }^{23}$ and Liau et al. ${ }^{24}$ reported, respectively, the $\mathrm{I} \cdots \mathrm{Au}^{\mathrm{I}}$ and $\mathrm{Cl} \cdots \mathrm{Au}^{\mathrm{I}}$ contacts, which can be interpreted as $\mathrm{X} \cdots \mathrm{Au}^{\mathrm{I}}$ halogen bonds, but the nature of these contacts was not verified. Finally, Blakey et $a l^{25}$ observed contacts between the typical XB donors such as iodoperfluorobenzenes and gold nanoparticles in water solutions, but these halogen bonds were confirmed only by indirect methods such as UV-vis difference spectroscopy, SERS, and XPS and the geometrical parameters were not obtained.

It is important that a metal atom can be an XB acceptor if it contains at least one lone pair, which could interact with empty $\sigma^{*}$-orbitals of an XB donor. In particular, some $\mathrm{d}^{8}-\mathrm{Pt}^{\mathrm{II}}$ and $\mathrm{d}^{8}-\mathrm{Rh}^{\mathrm{I}}$ centers may behave similarly to $\mathrm{d}^{10}-\mathrm{Au}^{\mathrm{I}}$ ones as these centers feature lone pairs on $4 \mathrm{~d}_{z^{2}}$ or $5 \mathrm{~d}_{z^{2}}$ orbitals. In particular, weak contacts were observed between some $\mathrm{d}^{8}-\mathrm{Pt}^{\mathrm{II}}$ and $\mathrm{d}^{8}-\mathrm{Rh}^{\mathrm{I}}$ species and iodine. ${ }^{16-19}$ These two were the only reports on unambiguous recognition of metal-involving $\mathrm{XB}$.

Taking into account that no data for $\mathrm{XB}$ between metal centers and halocarbons were published, we focused our efforts 

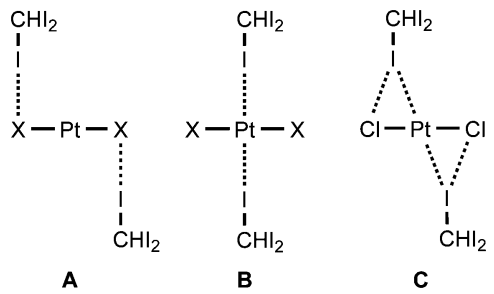

Chart 1 Three types of $\mathrm{XB}$ between the linear $\mathrm{Pt} \mathrm{X}_{2}(\mathrm{X}=\mathrm{Cl}, \mathrm{Br})$ fragment and two $\mathrm{CH}_{3}$ molecules.

on the search of metal-involving $\mathrm{XB}$ and we applied platinum(II) species as potential $\mathrm{XB}$ donors and iodoform as an XB acceptor.

In the current work, we report that the dialkylcyanamide $\mathrm{d}^{8}-\mathrm{Pt}^{\mathrm{II}}$ complexes trans $-\left[\mathrm{PtX}_{2}\left(\mathrm{NCNR}_{2}\right)_{2}\right]\left(\mathrm{R}_{2}=\mathrm{Me}_{2}, \mathrm{X}=\mathrm{Cl} \mathbf{1 a}, \mathrm{Br}\right.$ 1b; $\mathrm{Et}_{2} 2,\left(\mathrm{CH}_{2}\right)_{4} 3,\left(\mathrm{CH}_{2}\right)_{5}$ 4) easily co-crystallize with iodoform taken as the $\mathrm{XB}$ donor. We observed that $\mathrm{CHI}_{3}$ tends to co-crystallize with $\mathbf{1 a}-\mathbf{b}$ and $\mathbf{4}$ forming $\mathrm{HI}_{2} \mathrm{C}-\mathrm{I} \cdots$ Pt metal-involving halogen bonds (Chart 1, B) that fulfill both structural IUPAC criteria for halogen bonding. The existence of metal-involving halogen bonding has also been confirmed theoretically by the combination of DFT and $\mathrm{AIM}^{26}$ methods. Within the AIM theory, the $(3,-1)$ critical points (bond critical points, BCPs) on the surface of the theoretical electron density function $\rho(r)$ unambiguously reveal all bonding intermolecular interactions, including non-covalent interactions. Energies for the corresponding contacts $E_{\text {int }}$ can be determined using semi-empirical correlations between local energy densities in BCPs and interaction strength. ${ }^{27,28}$ Moreover, we found and confirmed theoretically by combination of DFT and AIM methods the unique bifurcated $\mathrm{HI}_{2} \mathrm{C}-\mathrm{I} \cdots \eta_{(\mathrm{Pt}-\mathrm{Cl})}^{2}(\mathrm{C}) \mathrm{XB}$ that undergoes thermally induced reversible $\mathrm{HI}_{2} \mathrm{C}-\mathrm{I} \cdots \eta_{(\mathrm{Pt}-\mathrm{Cl})}^{2} \rightleftarrows$ $\mathrm{HI}_{2} \mathrm{C}-\mathrm{I} \cdots \eta_{(\mathrm{Pt})}^{1}$ transformation.

Complexes $1 \mathbf{a}$ and $\mathbf{1 b}$ form isostructural associates $\mathbf{1 a} \cdot \frac{1}{2} \mathrm{CHCl}_{3}$. $1 \frac{1}{2} \mathrm{CHI}_{3}, \mathbf{1 a} \cdot 2 \mathrm{CHI}_{3}$, and $1 \mathbf{b} \cdot 2 \mathrm{CHI}_{3}$ upon crystallization from 1a: $\mathrm{CHI}_{3}=1: 2$ (molar ratio) solutions in chloroform or dichloromethane, or from $1 \mathbf{b}: \mathrm{CHI}_{3}=1: 2$ (molar ratio) solution in dichloromethane, respectively. Apart from numerous $\mathrm{HI}_{2} \mathrm{C}-$ $\mathrm{I} \cdots \mathrm{X}-\mathrm{Pt}$ halogen bonds (Chart 1, A), they exhibit the $\mathrm{HI}_{2} \mathrm{C}-\mathrm{I} \cdots \mathrm{Pt}$ short contacts, which can be interpreted as metal-involving $\mathrm{XB}$ accordingly to both structural IUPAC criteria as the distances I . . Pt (3.4276(5) $\AA$, 3.4389(5) $\AA$, and 3.4023(5) $\AA$ ) are less than sums of Bondi's ${ }^{29} \mathrm{vdW}$ radii $\left(R_{\mathrm{vdW}}(\mathrm{Pt})+R_{\mathrm{vdW}}(\mathrm{I})=3.73 \AA\right)$ and the corresponding angles $\left(164.84(17)^{\circ}, 169.8(3)^{\circ}\right.$, and $\left.172.7(2)^{\circ}\right)$ are close to $180^{\circ}$ (for more details see Section XR2 of the ESI $\dagger$ ). We also confirmed the formation of the I. .P. non-covalent interaction in $\mathbf{1 a} \cdot \frac{1}{2} \mathrm{CHCl}_{3} \cdot 1 \frac{1}{2} \mathrm{CHI}_{3}$ and $\mathbf{1 b} \cdot 2 \mathrm{CHI}_{3}$ systems theoretically for the 1a. $\left(\mathrm{CHI}_{3}\right)_{6}$ and $\mathbf{1 b} \cdot\left(\mathrm{CHI}_{3}\right)_{6}$ model structures by using Bader's AIM analysis (Fig. 1 and 2; for details see Section TH1 in the ESI $\dagger$ ). The estimated energies $\left(E_{\text {int }}\right)$ of these contacts are in the ranges of $2.4-2.8 \mathrm{kcal} \mathrm{mol}^{-1}$ and $2.7-3.1 \mathrm{kcal} \mathrm{mol}^{-1}$, respectively. The strength of these weak interactions has been defined according to the procedures proposed by Espinosa et $a .^{27}$ and Vener et al. ${ }^{28}$ these approaches considered explore linear relationships between the local electronic potential $V(r)$ and kinetic $G(r)$ densities at the bond critical points and energies of appropriate contacts.
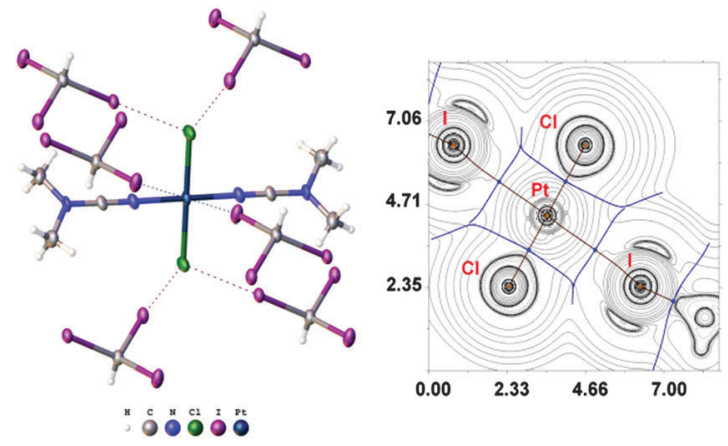

Fig. 1 Left: View of fragment $1 \mathrm{a} \cdot\left(\mathrm{CHI}_{3}\right)_{6}$ from $1 \mathrm{a} \cdot \frac{1}{2} \mathrm{CHCl}_{3} \cdot 1 \frac{1}{2} \mathrm{CHI}_{3}$. Thermal ellipsoids are shown with $50 \%$ probability and short contacts are indicated by dotted lines. Coordinates of this fragment were applied in further DFT calculations. Right: Contour line diagram of the Laplacian distribution $\nabla^{2} \rho(r)$ (cross-section along the plane $\mathrm{Pt}-\mathrm{Cl}-\mathrm{l}$ ) was received as a result of the topological analysis of the electron density distribution in the model structure. Bond paths are shown as brown lines, selected zero-flux surfaces - as blue lines, bond critical points $(3,-1)$ are shown in blue, nuclear critical points $(3,-3)$ - in pale brown, length unit - $\AA$.

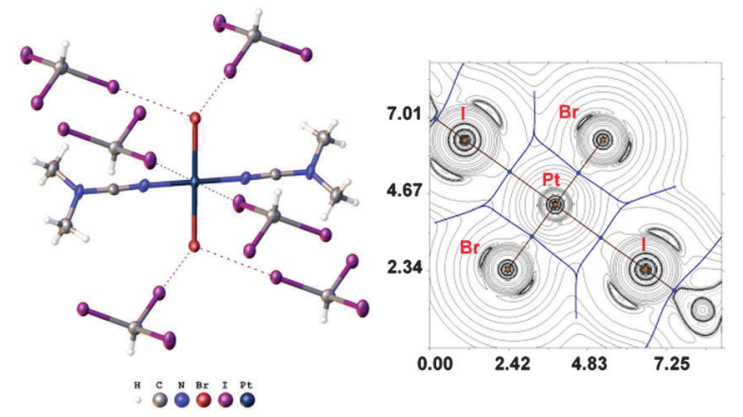

Fig. 2 Left: View of fragment $\mathbf{1 b} \cdot\left(\mathrm{CHI}_{3}\right)_{6}$ from $\left.\mathbf{1 b} \cdot 2 \mathrm{CH}\right]_{3}$. Thermal ellipsoids are shown with $50 \%$ probability and short contacts are indicated by dotted lines. Coordinates of this fragment were applied in further DFT calculations. Right: Contour line diagram of the Laplacian distribution $\nabla^{2} \rho(r)$ (cross-section along the plane $\mathrm{Pt}-\mathrm{Br}-\mathrm{l}$ ) was received as a result of the topological analysis of the electron density distribution in the model structure. Bond paths are shown as brown lines, selected zero-flux surfaces - as blue lines, bond critical points $(3,-1)$ are shown in blue, nuclear critical points $(3,-3)$ - in pale brown, length unit - $\AA$.

Complex 4 was co-crystallized with $\mathrm{CHI}_{3}$ in a $1: 2$ molar ratio from chloroform solution forming $\mathbf{4} \cdot 2 \mathrm{CHI}_{3}$. Apart from two types of $\mathrm{HI}_{2} \mathrm{C}-\mathrm{I} \cdots \mathrm{Cl}-\mathrm{Pt} \mathrm{XB}(\mathrm{Chart} 1, \mathbf{A})$, this solid also contains the bifurcated $\mathrm{HI}_{2} \mathrm{C}-\mathrm{I} \cdots \eta_{(\mathrm{Pt}-\mathrm{Cl})}$ metal-involving $\mathrm{XB}(\mathrm{C})$. Both distances $(d(\mathrm{I} \cdots \mathrm{Pt})=3.7060(7) \AA$ and $d(\mathrm{I} \cdots \mathrm{Cl})=3.6974(19) \AA)$ are slightly less than the corresponding sums of Bondi's ${ }^{29} \mathrm{vdW}$ $\operatorname{radii}\left(R_{\mathrm{vdw}}(\mathrm{Pt})+R_{\mathrm{vdw}}(\mathrm{I})=3.73 \AA ; R_{\mathrm{vdw}}(\mathrm{Cl})+R_{\mathrm{vdw}}(\mathrm{I})=3.73 \AA\right)$ and both contact angles are not much different from $160^{\circ}$ $\left(\angle(\mathrm{C}-\mathrm{I} \cdots \mathrm{Pt})=158.4(2)^{\circ}, \angle(\mathrm{C}-\mathrm{I} \cdots \mathrm{Cl})=163.4(2)^{\circ}\right)$ (see Section XR2 of the ESI $\dagger)$. The formation of the I $\cdots$ Pt and I $\cdots \mathrm{Cl}$ noncovalent interactions was confirmed theoretically for the $4 \cdot\left(\mathrm{CHI}_{3}\right)_{6}$ model structure by using Bader's AIM analysis (Fig. 3, see also TH1 of the ESI $\dagger$ ). The estimated energies $E_{\text {int }}$ of these contacts are in good agreement with the energy range for $\mathrm{XB}\left(1.3-1.4 \mathrm{kcal} \mathrm{mol}^{-1}\right.$ for $\mathrm{HI}_{2} \mathrm{C}-\mathrm{I} \cdots \mathrm{Cl}$ and $1.6 \mathrm{kcal} \mathrm{mol}^{-1}$ for $\mathrm{HI}_{2} \mathrm{C}-\mathrm{I} \cdots \mathrm{Pt}$ ). To the best of our knowledge, these weak 

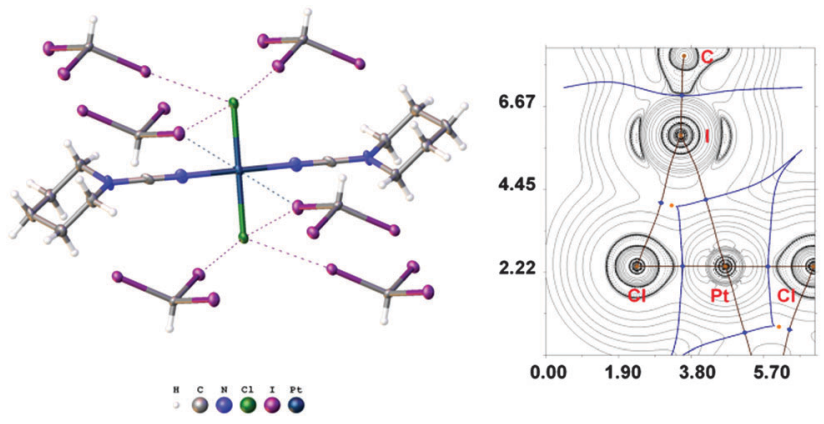

Fig. 3 Left: View of fragment $4 \cdot\left(\mathrm{CHI}_{3}\right)_{6}$ from $4 \cdot 2 \mathrm{CH}_{3}$. Thermal ellipsoids are shown with $50 \%$ probability and short contacts are indicated by dotted lines. Coordinates of this fragment were applied in further DFT calculations. Right: Contour line diagram of the Laplacian distribution $\nabla^{2} \rho(r)$ (cross-section along the plane $\mathrm{Pt}-\mathrm{Cl}-\mathrm{I}$ ) was received as a result of the topological analysis of the electron density distribution in the model structure. Bond paths are shown as brown lines, selected zero-flux surfaces - as blue lines, bond critical points $(3,-1)$ are shown in blue, ring critical points $(3,+1)$ - in orange, nuclear critical points $(3,-3)-$ in pale brown, length unit - $\AA$.

interactions are the first example of metal-involving bifurcated $\mathrm{XB}$. It is noteworthy that examples of metal-free bifurcated $\mathrm{XB}^{6}$ and metal-involving bifurcated hydrogen bonding ${ }^{30}$ are known. Taking into account that the observed distances within the $\mathrm{HI}_{2} \mathrm{C}-\mathrm{I} \cdots \eta^{2}{ }_{(\mathrm{Pt}-\mathrm{Cl})}$ moiety are only slightly less than their van der Waals separations, more examples of metal-involving bifurcates are needed to exclude completely the packing effects on the bonding.

Variable temperature XRD experiments for the same singlecrystal of $4 \cdot 2 \mathrm{CHI}_{3}$ were performed at $100,150,200,250$, and $300 \mathrm{~K}$. An inspection of the obtained data indicates that the heating leads only to the elongation of the intermolecular distances, whereas the covalent bond lengths remain almost the same. The most significant changes were detected for the bifurcated $\mathrm{HI}_{2} \mathrm{C}-\mathrm{I} \cdots \eta^{2}{ }_{(\mathrm{Pt}-\mathrm{Cl})}$ contacts (by $0.08 \AA$ upon an increase in temperature from 100 to $300 \mathrm{~K}$ ), whereas the $\mathrm{HI}_{2} \mathrm{C}-\mathrm{I} \cdots \mathrm{Cl}-\mathrm{Pt}$ halogen bonds were lengthened by only 0.05 and $0.03 \AA$, correspondingly (see also XR3 of the ESI $\dagger$ ). Bader's AIM analysis (TH2 of ESI $\dagger$ ) for the 4. $\left(\mathrm{CHI}_{3}\right)_{6}$ model systems at each temperature indicated above showed the gradual reduction of the estimated energies of all halogen bonds. Apart from that one of the bond critical points (between $\mathrm{Cl}$ and I) in the bifurcated XB disappeared on going from 250 to $300 \mathrm{~K}$. The reversibility of the thermal transformation was proved by three consecutive XRD experiments for the same single-crystal at $100 \mathrm{~K}, 300 \mathrm{~K}$, and again at $100 \mathrm{~K}$. This experiment gives evidence supporting the thermally induced reversible $\mathrm{HI}_{2} \mathrm{C}-\mathrm{I} \cdots \eta_{(\mathrm{Pt}-\mathrm{Cl})}^{2} \rightleftarrows$ $\mathrm{HI}_{2} \mathrm{C}-\mathrm{I} \cdots \eta_{(\mathrm{Pt})}^{1}$ transformation.

Complexes 2 and 3 were co-crystallized with $\mathrm{CHI}_{3}$ in a $1: 2$ molar ratio from chloroform solutions forming $2 \cdot 2 \mathrm{CHI}_{3}$ and $3 \cdot 2 \mathrm{CHI}_{3}$, respectively. These associates were found to form only three types of $\mathrm{HI}_{2} \mathrm{C}-\mathrm{I} \cdots \mathrm{Cl}-\mathrm{Pt} \mathrm{XB}$ in each case (Fig. 4 and 5). In all cases $\left(\mathbf{1} \mathbf{a} \cdot \frac{1}{2} \mathrm{CHCl}_{3} \cdot 1 \frac{1}{2} \mathrm{CHI}_{3}, \mathbf{1 b} \cdot 2 \mathrm{CHI}_{3}, 2 \cdot 2 \mathrm{CHI}_{3}, 3 \cdot 2 \mathrm{CHI}_{3}\right.$, and $4 \cdot 2 \mathrm{CHI}_{3}$ ), the formation of halogen bonds with the halide ligands was confirmed theoretically by using Bader's AIM
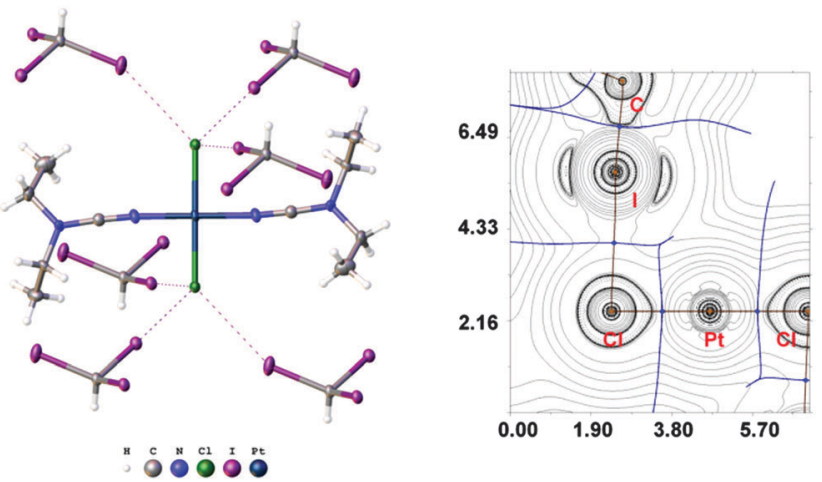

Fig. 4 Left: View of fragment $\mathbf{2} \cdot\left(\mathrm{CH}_{3}\right)_{6}$ from $\left.\mathbf{2} \cdot 2 \mathrm{CH}\right)_{3}$. Thermal ellipsoids are shown with $50 \%$ probability and short contacts are indicated by dotted lines. Coordinates of this fragment were applied in further DFT calculations. Right: Contour line diagram of the Laplacian distribution $\nabla^{2} \rho(r)$ (cross-section along the plane $\mathrm{Pt}-\mathrm{Cl}-\mathrm{I}$ ) was received as a result of the topological analysis of the electron density distribution in the model structure. Bond paths are shown as brown lines, selected zero-flux surfaces - as blue lines, bond critical points $(3,-1)$ are shown in blue, nuclear critical points $(3,-3)$ - in pale brown, length unit $-\AA$.

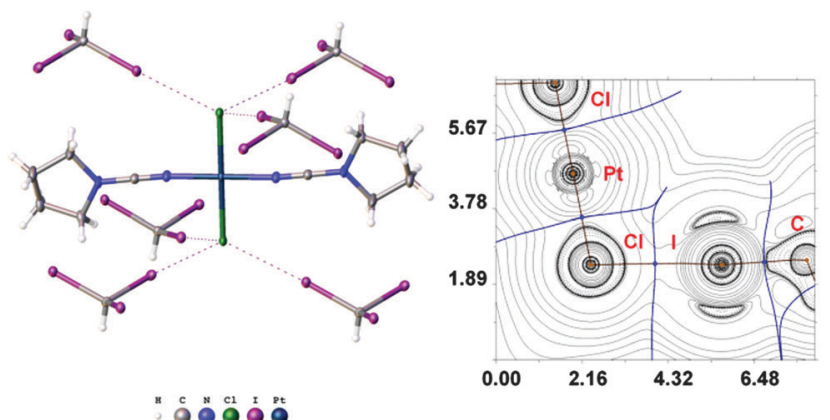

Fig. 5 Left: View of fragment $3 \cdot\left(\mathrm{CHI}_{3}\right)_{6}$ from $3 \cdot 2 \mathrm{CHI}_{3}$. Thermal ellipsoids are shown with $50 \%$ probability and short contacts are indicated by dotted lines. Coordinates of this fragment were applied in further DFT calculations. Right: Contour line diagram of the Laplacian distribution $\nabla^{2} \rho(r)$ (cross-section along the plane $\mathrm{Pt}-\mathrm{Cl}-\mathrm{l}$ ) was received as a result of the topological analysis of the electron density distribution in the model structure. Bond paths are shown as brown lines, selected zero-flux surfaces - as blue lines, bond critical points $(3,-1)$ are shown in blue, nuclear critical points $(3,-3)$ - in pale brown, length unit - $\AA$.

analysis (XR2 and TH1 of the ESI $\dagger$ ). The estimated energies $\left(E_{\text {int }}\right)$ of this type of weak interaction are in the range of 1.9$3.5 \mathrm{kcal} \mathrm{mol}{ }^{-1}$. Only the $\mathrm{HI}_{2} \mathrm{C}-\mathrm{I} \cdots \mathrm{Cl}^{-}$and the $\mathrm{HI}_{2} \mathrm{C}-\mathrm{I} \cdots \mathrm{Br}^{-}$ weak interactions were previously described, ${ }^{31}$ but no single example of the XB between metal-coordinated chloride or bromide and $\mathrm{CHI}_{3}$ has been previously reported.

The elongation of the $\mathrm{Pt}-\mathrm{X}(\mathrm{X}=\mathrm{Cl}, \mathrm{Br})$ bonds in the $\mathrm{CHI}_{3}$-associates was detected when XRD data of the associates were compared with those of $\mathrm{CHI}_{3}$-free $1 \mathrm{aa},{ }^{32} \mathbf{1 b}$, and $\mathbf{4}^{33}$ (see $\mathrm{XR} 1$ in the ESI $\dagger$ ). The Pt-Cl distances in $2 \cdot 2 \mathrm{CHI}_{3}$ and $3 \cdot 2 \mathrm{CHI}_{3}$ are longer than in $\mathrm{CHI}_{3}$-free complexes $\mathbf{1 a}$ and 4 . Although these differences are not too large (0.01-0.03 $\AA)$, the observed elongation indirectly point out (Chart 2) to the presence of the $\mathrm{HI}_{2} \mathrm{C}-\mathrm{I} \cdots \mathrm{X}-\mathrm{Pt}$ and $\mathrm{HI}_{2} \mathrm{C}-\mathrm{I} \cdots \mathrm{Pt}$ contacts (see XR2 and TH1 in the ESI $\dagger$ ) additionally supporting our conclusions. 


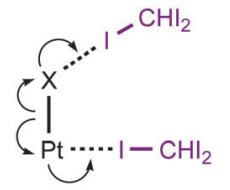

Chart 2 The $\mathrm{Pt}-\mathrm{X}$ bond elongation caused by the $\mathrm{HI}_{2} \mathrm{C}-\mathrm{I}$. X $\mathrm{X}-\mathrm{Pt}$ and $\mathrm{HI}_{2} \mathrm{C}-\mathrm{I} \ldots \mathrm{Pt}$ weak interactions.

In this communication, we reported the first examples of definite and unambiguous identification of metal-involving XB with halocarbons, viz. between $\mathrm{Pt}^{\mathrm{II}}$ and $\mathrm{CHI}_{3}$. Various $\mathrm{Pt}^{\mathrm{II}}$ centers are known to participate in donor-acceptor interactions with Lewis acids ( $\mathrm{B}^{\mathrm{III}}$ and $\mathrm{S}^{\mathrm{IV}}$ compounds ${ }^{34,35}$ ), but in all cases these donor-acceptor bonds are too strong to be treated as non-covalent bonds. The most relevant example of XB is weak contacts between the $\mathrm{Pt}^{\mathrm{II}}$ and $\mathrm{Rh}^{\mathrm{I}}$ centers and iodine. ${ }^{16-19}$ Examples of the $\mathrm{X} \cdots \mathrm{M}$ short contacts given in the Introduction have not been clearly identified as metal-involving XB. We plan to continue our studies in the area of metal-involving $\mathrm{XB}$ and to expand the range of studied systems to other X's and X-containing species (e.g. $\mathrm{Br}$ ) and metal centers (e.g. $\left.\mathrm{Pd}^{\mathrm{II}}\right)$ and studies in these directions are underway in our group.

The authors express their gratitude to the Russian Science Foundation for grant (14-13-00060) supporting their synthetic and structural studies. ASN thanks the Russian Foundation for Basic Research for grant (16-33-60063) focused on theoretical calculations of XB. IVA is grateful to the Russian Foundation for Basic Research for financial support of variable temperature XRD studies (grant 16-33-60133). Physicochemical studies were performed at the Center for X-ray Diffraction Studies, Magnetic Resonance Research Center, and Center for Chemical Analysis and Materials Research (all belong to Saint Petersburg State University).

\section{References}

1 R. Bertani, P. Sgarbossa, A. Venzo, F. Lelj, M. Amati, G. Resnati, T. Pilati, P. Metrangolo and G. Terraneo, Coord. Chem. Rev., 2010, 254, 677-695.

2 G. Cavallo, P. Metrangolo, T. Pilati, G. Resnati, M. Sansotera and G. Terraneo, Chem. Soc. Rev., 2010, 39, 3772-3783.

3 E. Persch, O. Dumele and F. Diederich, Angew. Chem., Int. Ed., 2015, 54, 3290-3327.

4 P. Auffinger, F. A. Hays, E. Westhof and P. S. Ho, Proc. Natl. Acad. Sci. U. S. A., 2004, 101, 16789-16794.

5 P. S. Ho, Halogen Bonding I: Impact on Materials Chemistry and Life Sciences, Springer-Verlag Berlin, Berlin, 2015, vol. 358, pp. 241-276.

6 K. B. Landenberger, O. Bolton and A. J. Matzger, J. Am. Chem. Soc., $2015,137,5074-5079$.
7 H. Wang, R. X. Hu, X. Pang, H. Y. Gao and W. J. Jin, CrystEngComm, 2014, 16, 7942-7948.

8 V. V. Sivchik, A. I. Solomatina, Y.-T. Chen, A. J. Karttunen, S. P. Tunik, P.-T. Chou and I. O. Koshevoy, Angew. Chem., Int. Ed., 2015, 54, 14057-14060.

9 G. R. Desiraju, P. S. Ho, L. Kloo, A. C. Legon, R. Marquardt, P. Metrangolo, P. Politzer, G. Resnati and K. Rissanen, Pure Appl. Chem., 2013, 85, 1711-1713.

10 K. Rissanen, CrystEngComm, 2008, 10, 1107-1113.

11 S. V. Rosokha, C. L. Stern and J. T. Ritzert, Chem. - Eur. J., 2013, 19, 8774-8788.

12 D. A. Bahnick, W. E. Bennett and W. B. Person, J. Phys. Chem., 1969, 73, 2309-2316.

13 T. Mager, H. Bertagnolli, D. Degenhardt and R. Frahm, Mol. Phys., $1991,73,587-601$.

14 H. G. Lohr, A. Engel, H. P. Josel, F. Vogtle, W. Schuh and H. Puff, J. Org. Chem., 1984, 49, 1621-1627.

15 J. Viger-Gravel, S. Leclerc, I. Korobkov and D. L. Bryce, J. Am. Chem. Soc., 2014, 136, 6929-6942.

16 J. A. M. van Beek, G. van Koten, G. Dekker, E. Wissing, M. C. Zoutberg and C. H. Stam, J. Organomet. Chem., 1990, 394, 659-678.

17 J. A. M. van Beek, G. van Koten, W. J. J. Smeets and A. L. Spek, J. Am. Chem. Soc., 1986, 108, 5010-5011.

18 R. A. Gossage, A. D. Ryabov, A. L. Spek, D. J. Stufkens, J. A. M. van Beek, R. van Eldik and G. van Koten, J. Am. Chem. Soc., 1999, 121, 2488-2497.

19 D. W. Shaffer, S. A. Ryken, R. A. Zarkesh and A. F. Heyduk, Inorg. Chem., 2012, 51, 12122-12131.

20 J. H. Chen, Y. M. Liu, J. X. Zhang, Y. Y. Zhu, M. S. Tang, S. W. Ng and G. Yang, CrystEngComm, 2014, 16, 4987-4998.

21 C. Wölper, S. R. Piñol, S. D. Ibáñez, M. Freytag, P. G. Jones and A. Blaschette, Z. Anorg. Allg. Chem., 2008, 634, 1506-1516.

22 A. Laguna, T. Lasanta, J. M. Lopez-de-Luzuriaga, M. Monge, P. Naumov and M. E. Olmos, J. Am. Chem. Soc., 2010, 132, 456-457.

23 H. M. Yamamoto, J. I. Yamaura and R. Kato, J. Am. Chem. Soc., 1998, 120, 5905-5913.

24 R. Y. Liau, H. Ehlich, A. Schier and H. Schmidbaur, Z. Naturforsch., B: J. Chem. Sci., 2002, 57, 1085-1089.

25 I. Blakey, Z. Merican, L. Rintoul, Y. M. Chuang, K. S. Jack and A. S. Micallef, Phys. Chem. Chem. Phys., 2012, 14, 3604-3611.

26 R. F. W. Bader, Atoms in Molecules: A Quantum Theory, Oxford University Press, Oxford, 1990.

27 E. Espinosa, E. Molins and C. Lecomte, Chem. Phys. Lett., 1998, 285, 170-173.

28 M. V. Vener, A. N. Egorova, A. V. Churakov and V. G. Tsirelson, J. Comput. Chem., 2012, 33, 2303-2309.

29 A. Bondi, J. Phys. Chem., 1964, 68, 441-451.

30 D. Braga, F. Grepioni, E. Tedesco, K. Biradha and G. R. Desiraju, Organometallics, 1997, 16, 1846-1856.

31 H. Bock and S. Holl, Z. Naturforsch., B: J. Chem. Sci., 2001, 56, 152-163.

32 N. A. Bokach, T. B. Pakhomova, V. Y. Kukushkin, M. Haukka and A. J. L. Pombeiro, Inorg. Chem., 2003, 42, 7560-7568.

33 P. V. Gushchin, N. A. Bokach, M. Haukka, E. S. Dmitrieva and V. Y. Kukushkin, Acta Crystallogr., Sect. E: Struct. Rep. Online, 2006, 62, $\mathrm{m} 244-\mathrm{m} 246$

34 S. Bontemps, M. Sircoglou, G. Bouhadir, H. Puschmann, J. A. K. Howard, P. W. Dyer, K. Miqueu and D. Bourissou, Chem. - Eur. J., 2008, 14, 731-740.

35 P. Steenwinkel, H. Kooijman, W. J. J. Smeets, A. L. Spek, D. M. Grove and G. van Koten, Organometallics, 1998, 17, 5411-5426. 